\title{
Commentary Understanding cardiac output
} Jean-Louis Vincent

Department of Intensive Care, Erasme Hospital, Université libre de Bruxelles, Route de Lennik 808, 1070-B Brussels, Belgium

Corresponding author: Jean-Louis Vincent, jvincen@ulb.ac.be

Published: 22 August 2008

This article is online at http://ccforum.com/content/12/4/174

(c) 2008 BioMed Central Ltd
Critical Care 2008, 12:174 (doi:10.1186/cc6975)

can be pumped over a particular period of time. Using our analogy, the faster the cyclist pedals, the faster the bicycle will go. But things are not quite so simple! Staying with the bicycle analogy, it is easy to imagine that if the cyclist pedals too fast for too long, he/she will get tired and be unable to maintain the rate of pedaling, so the bicycle will slow. There is an optimal rate of pedaling: too fast and the cyclist will tire too quickly and have to slow down; too slow and the bicycle will not move fast enough to cover the required distance. Similarly, if the heart rate is too slow, usually easily identified as part of a severe bradyarrhythmia, or is too fast, then cardiac output can be impaired. Acute supraventricular or ventricular tachycardia may also be a cause of low cardiac output, and even of cardiogenic shock.

\section{Contractility}

Clearly, if the cyclist flexes his/her muscles a little and pushes harder on the pedals, then the bicycle will move faster. This can be equated to an increased contractility of the heart muscle, resulting in increased cardiac output. Too little pedal power, or impaired contractility, will reduce cardiac output; however, too much effort will result in fatigue, sometimes leading to a complete collapse, with the need to slow down substantially or even to stop. This may occur with excessive inotropic support, resulting in increased mortality rates.

\section{Preload}

Preload is the degree of myocardial distension prior to shortening. As initially demonstrated by Otto Frank and Ernest Starling, an intrinsic property of myocardial cells is that the force of their contraction depends on the length to which they are stretched: the greater the stretch (within certain limits), the greater the force of contraction. An increase in the distension of the ventricle will therefore result in an increase in the force of contraction, which will increase cardiac output. In our analogy, preload can be compared with a tailwind allowing the cyclist to move faster without any additional muscular effort. Of course, unlike our analogy - in which the speed of the bicycle will continue to increase as the speed of the wind increases - in the heart a preload value will

\section{The analogy and the four determinants of cardiac output \\ Heart rate}

The heart rate is perhaps the simplest determinant of cardiac output to visualize: the faster the heart beats, the more blood 
Figure 1

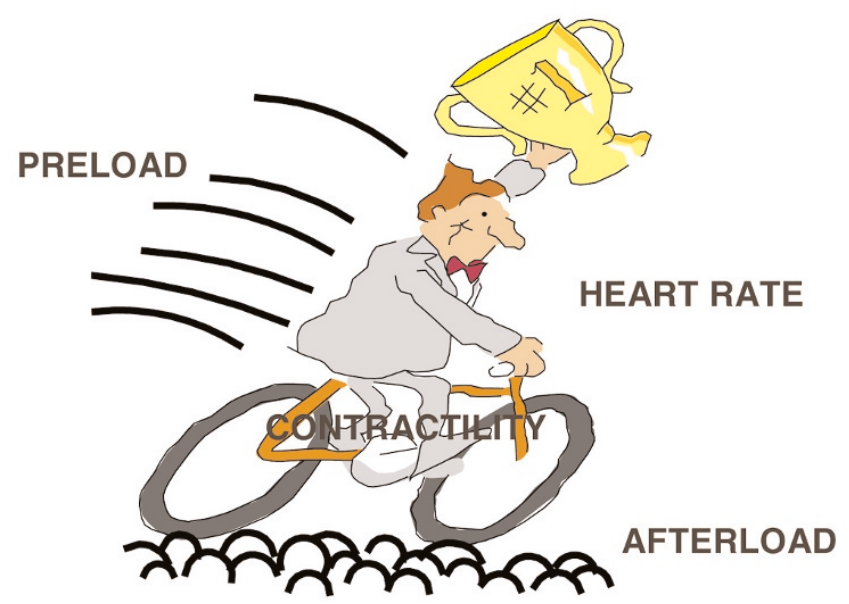

Four determinants of cardiac output, using an analogy to the speed of a bicycle.

eventually be reached at which cardiac output will no longer increase.

Preload largely depends on the amount of ventricular filling. It should not, however, be confused with the venous return. In our analogy, the venous return is like the speed of the bicycle coming towards us. The amount of blood returning to the heart in any period of time must be equal to the amount of blood pumped by the heart in the same period, as there is no place for storage of blood in the heart. Venous return therefore equals cardiac output, whereas preload is only one component of cardiac output.

\section{Afterload}

Afterload is the force against which the ventricles must act in order to eject blood, and is largely dependent on the arterial blood pressure and vascular tone. By cycling on a large smooth road rather than a narrow, bumpy one, or on a road with a gentle downhill slope, the bicycle's speed can increase significantly for a given degree of muscular effort. A tired cyclist is particularly sensitive to these aspects. Similarly, reducing afterload can increase cardiac output, especially in conditions where contractility is impaired.

\section{Some clinical applications Myocardial depression of sepsis}

Sepsis is usually associated with a normal or high cardiac output; yet many studies have shown that myocardial depression can occur even early in the course of sepsis [1], so why is cardiac output not reduced? The pathophysiology of sepsis involves the release of cytokines, some of which are associated with abnormal calcium handling by the cardiac myocytes [2], leading to reduced myocardial contraction. Because of the simultaneous tachycardia and reduced vascular tone, however, afterload is reduced - and cardiac output can therefore be maintained or even increased. In addition, the hyperkinetic state seen in sepsis is typically preceded by fluid therapy. This situation is akin to the cyclist being too tired to push on the pedals, but being able to keep up speed because of a smooth downward sloping road.

\section{Deleterious effects of inotropic therapy}

As the long-distance cyclist will know, prolonged strenuous exercise can lead to high tissue oxygen demands, which can later result in impaired muscle contraction and poor performance. Positive inotropic drugs act by different mechanisms to increase the contractility of the heart, and as such have been proposed for use in patients with cardiac failure to increase myocardial contractility and hence cardiac output. Indeed, in the short-term, acute phase of heart failure, inotropic drugs can be useful to increase cardiac output. When considered in light of our analogy, however, it is easy to appreciate that excessive inotropic stimulation may increase the myocardial oxygen demand, leading ultimately to myocardial ischemia. Indeed, prolonged stimulation with longterm inotropic therapy has been shown to increase mortality rates in patients with chronic heart failure [3-5]. In contrast, reducing the force of contraction may enable the cyclist to pedal longer; this may account for some of the beneficial effects of prolonged $\beta$-blockade therapy in the treatment of heart failure.

\section{Beneficial effects of vasodilating substances}

Arterial vasodilator therapy results in significant improvements in cardiac output in patients with heart failure by reducing afterload (cycling downhill). Interestingly, this therapeutic approach has been more successful than inotropic stimulation, and has been shown to reduce mortality rates in this patient population $[6,7]$. An obvious limitation is the decrease in arterial pressure, which may compromise organ perfusion.

\section{Potentially harmful effects of vasopressor agents}

In contrast to the beneficial effects of vasodilator drugs, the administration of strong vasopressors may decrease cardiac output by increasing afterload, even in individuals with normal cardiac function. This effect is seen, for example, with phenylephrine, which has almost pure $\alpha$-adrenergic effects. Vasopressin may also decrease cardiac output by increasing vascular tone [8-10]. Considering our analogy, this effect may be expected - increasing the slope of the road, or making the surface too uneven, will eventually force most cyclists to get off their bicycles and walk, thus reducing their speed considerably!

Even norepinephrine, which has some $\beta$-adrenergic properties, may decrease cardiac output in the absence of a reduction in vascular tone. The cyclist is pushing a bit harder on the bicycle's pedals, but as the road is now going uphill the bicycle's speed may decrease considerably. High doses of norepinephrine have been used as an experimental model of heart failure [11-13]. 


\section{Effects of inodilating substances}

Some drugs, such as phosphodiesterase inhibitors (milrinone, enoximone) and levosimendan, exert some inotropic effects in addition to vasodilating effects. This is analogous to pushing a bit harder on the bicycle's pedals at the same time as you pass the top of a hill and the road starts to go down again; the greater exertion may lead to fatigue, but the downhill slope helps to maintain speed. This is why these agents may increase myocardial oxygen requirements less than other inotropic drugs.

\section{Effects of fluid administration}

Fluid administration takes advantage of the Frank-Starling relationship to increase stroke volume and cardiac output. Although an excessive increase in the end-diastolic volume may increase myocardial oxygen requirements, this intervention is associated with relatively limited consequences, as compared with catecholamines. Fluid administration is like adding a tailwind to the cyclist.

\section{Effects of calcium entry blockers on cardiac output}

As calcium is essential to myocardial contraction, calcium entry blockers are expected to decrease the force of contraction of the myocardium. This is observed in isolated myocardium, but not in living organisms, where the simultaneous decrease in vascular tone (especially with the dihydropyridine derivatives) helps to maintain and even increase cardiac output. The cyclist is tired, but the road is smoother, with a gentler upward slope!

\section{Conclusion}

The interpretation of cardiac output is not as straightforward as it may seem at first glance. Comparing the complex relationship of cardiac output and its four components with the speed of a bicycle and its determinants, however, can help us to understand some of the complex pathophysiological alterations in critical illness and to appreciate better the effects of various interventions on cardiac output.

\section{Competing interests}

The author declares that they have no competing interests.

\section{References}

1. Suffredini AF, Fromm RE, Parker MM, Brenner M, Kovacs JA, Wesley RA, Parrillo JE: The cardiovascular response of normal humans to the administration of endotoxin. $N$ Engl J Med 1989, 321:280-287.

2. Kinugawa K, Takahashi T, Kohmoto O, Yao A, Aoyaki T, Momomura S, Hirata $Y$, Serizawa T: Nitric oxide-mediated effects of interleukin- 6 on $\mathrm{Ca}^{2+} \mathrm{i}$ and cell contraction in cultured chick ventricular myocytes. Circ Res 1994, 75:285-295.

3. The Xamoterol in Severe Heart Failure Study Group: Xamoterol in severe heart failure. Lancet 1990, 336:1-6.

4. Packer M, Carver JR, Rodehoffer RJ, Ivanhoe RJ, DiBianco R, Zeldis SM, Hendrix GH, Bommer WJ, Elkayam U, Kukin ML, Mallis GI, Sollano JA, Shannon J, Tandon PK, Demets DL: Effect of oral milrinone on mortality in severe chronic heart failure. $N$ Engl J Med 1991, 325:1468-1475.

5. Cowley AJ, Skene AM: Treatment of severe heart failure: quantity or quality of life? A trial of enoximone. Enoximone Investigators. Br Heart J 1994, 72:226-230.
6. Cohn JN, Archibald DG, Ziesche S, Franciosa JA, Harston WE, Tristani FE, Dunkman WB, Jacobs W, Francis GS, Flohr KH: Effect of vasodilator therapy on mortality in chronic congestive heart failure. Results of a Veterans Administration Cooperative Study. N Engl J Med 1986, 314:1547-1552.

7. The SOLVD Investigators: Effect of enalapril on mortality and the development of heart failure in asymptomatic patients with reduced left ventricular ejection fractions. $N$ Engl J Med 1992, 327:685-691.

8. Berk JL, Hagen JF, Fried VJ: The effect of vasopressin on oxygen availability. Ann Surg 1979, 189:439-441.

9. Holmes CL, Patel BM, Russell JA, Walley KR: Physiology of vasopressin relevant to management of septic shock. Chest 2001, 120:989-1002.

10. Dunser MW, Mayr AJ, Ulmer H, Ritsch N, Knotzer H, Pajk W, Luckner G, Mutz NJ, Hasibeder WR: The effects of vasopressin on systemic hemodynamics in catecholamine-resistant septic and postcardiotomy shock: a retrospective analysis. Anesth Analg 2001, 93:7-13.

11. Rona G: Catecholamine cardiotoxicity. J Mol Cell Cardiol 1985, 17:291-306.

12. Todd GL, Baroldi G, Pieper GM, Clayton FC, Eliot RS: Experimental catecholamine-induced myocardial necrosis. I. Morphology, quantification and regional distribution of acute contraction band lesions. J Mol Cell Cardiol 1985, 17:317-338.

13. Lee JC, Downing SE: Ventricular function in norepinephrineinduced cardiomyopathic rabbits. Am J Physiol 1982, 242: $\mathrm{H} 191-\mathrm{H} 196$. 